\title{
An Evaluation of the Pharmacokinetics, Safety, and Tolerability of Aclidinium/Formoterol Fixed-Dose Combination Administered in Chinese Patients with Moderate-to-Severe Chronic Obstructive Pulmonary Disease
}

\author{
Hong Zhang ${ }^{1} \cdot$ Sami Z. Daoud ${ }^{2} \cdot$ Michael S. Gillen $^{2} \cdot$ Natalia Calderon $^{3} \cdot$ Maria Heijer $^{3} \cdot$ Eduard Molins $^{4}$. \\ Esther Garcia-Gil ${ }^{4} \cdot$ Hong Chen ${ }^{1} \cdot$ Qianqian $\mathrm{Li}^{1}$ - Chengjiao Liu ${ }^{1} \cdot$ Yanhua Ding ${ }^{1}$
}

Accepted: 28 November 2021 / Published online: 8 February 2022

(c) The Author(s) 2022

\begin{abstract}
Background and Objectives The aim of this study was to evaluate the pharmacokinetics, safety, and tolerability of aclidinium bromide/formoterol fumarate in patients from China with moderate-to-severe chronic obstructive pulmonary disease (COPD). Methods In this open-label, repeat-dose, 5-day pharmacokinetic study (NCT03276078) of inhaled aclidinium bromide/ formoterol fumarate 400/12 $\mu \mathrm{g}$ twice daily, plasma concentrations of aclidinium, formoterol, and two aclidinium metabolites (LAS34823, LAS34850) were assessed (days 1 and 5). Adverse event (AE) data were collected.

Results Twenty patients (15 [75\%] males) with a mean age of 59.2 years were included. Median (range) time to maximum concentration on days 1 and 5 was $0.08(0.08-0.50)$ and $0.08(0.08-0.50) \mathrm{h}$, respectively, for aclidinium; and $1.00(0.08-3.00)$ and $0.08(0.08-1.50) \mathrm{h}$, respectively, for formoterol. Mean elimination half-life and accumulation ratio for area under the concentration-time curve during a dosage interval $\left(\mathrm{AUC}_{\tau}\right)$ was $19.42 \mathrm{~h}$ and 2.0, respectively, for aclidinium; and $14.06 \mathrm{~h}$ and 1.4, respectively, for formoterol. Steady-state maximum concentration $\left(C_{\max , \mathrm{ss}}\right)$ and $\mathrm{AUC}_{\tau}$ on day 5 were $60.86 \mathrm{pg} / \mathrm{mL}$ and $168.80 \mathrm{~h} \cdot \mathrm{pg} / \mathrm{mL}$, respectively, for aclidinium; and $6.47 \mathrm{pg} / \mathrm{mL}$ and $31.98 \mathrm{~h} \cdot \mathrm{pg} / \mathrm{mL}$, respectively, for formoterol. Aclidinium produced high coefficients of variation (day $1: \mathrm{AUC}_{\tau} 79.0 \%, C_{\max } 84.5 \%$; day 5: $\mathrm{AUC}_{\tau} 82.2 \%, C_{\max } 150.0 \%$ ). Few AEs were reported, typically one per patient. One patient discontinued due to a serious $\mathrm{AE}$ (considered possibly unrelated to treatment). Conclusions Aclidinium/formoterol 400/12 $\mu \mathrm{g}$ twice daily was well-tolerated in patients from China with moderate-to-severe COPD. Safety findings were consistent with the known safety profile.
\end{abstract}

Clinical Trial Identifier ClinicalTrials.gov, NCT03276078.

Yanhua Ding

dingyanh@jlu.edu.cn; yanhuad2019@163.com

1 Phase I Clinical Trial Unit, The First Hospital, Jilin University, No 71, Xinmin Street, Changchun 130021, China

2 BioPharmaceuticals R\&D, AstraZeneca, Gaithersburg, MD, USA

3 BioPharmaceuticals R\&D, AstraZeneca, Gothenburg, Sweden

4 BioPharmaceuticals R\&D, AstraZeneca, Barcelona, Spain

\section{Key Points}

This study evaluated the pharmacokinetics, safety, and tolerability of inhaled aclidinium/formoterol for the treatment of moderate-to-severe chronic obstructive pulmonary disease in patients from China.

The demographic and baseline characteristics of the study population were found to be representative of the intended COPD patient population.

Safety outcomes were consistent with the known safety profile of aclidinium/formoterol from other patient populations. 


\section{Introduction}

Chronic obstructive pulmonary disease (COPD) is characterized by progressive airflow obstruction associated with chronic inflammation in the airways and lungs due to noxious particles or gases [1]. COPD is a leading cause of mortality worldwide and poses a significant global health burden [2]. In China, the prevalence of COPD is estimated to be as high as $8.2 \%$ in people aged over 40 years [3].

Long-acting muscarinic antagonists (LAMAs) have been shown to provide clinical benefits in the treatment of COPD by blocking muscarinic acetylcholine receptors in the bronchial smooth muscle, thereby decreasing cholinergic tone and relaxing the airways [1, 4]. In addition, long-acting $\beta_{2}$-agonists (LABAs) stimulate the bronchial smooth muscle, resulting in increased airway caliber [1]. This reduction in bronchoconstriction improves airflow, reduces breathlessness and COPD exacerbations, increases exercise tolerance, and improves quality of life $[1,5]$.

Clinical studies have shown that combination treatment with a LABA and a LAMA results in greater improvement in bronchodilation, as well as better symptom control, compared with monotherapies $[1,4,6]$. Consequently, several combinations of LABAs and LAMAs are approved for the treatment of COPD, including indacaterol/glycopyrronium [7, 8], vilanterol/umeclidinium [9], tiotropium/ olodaterol [10, 11], glycopyrrolate/formoterol [12, 13], and aclidinium/formoterol $[14,15]$. Of these, indacaterol/ glycopyrronium [16], vilanterol/umeclidinium [17] and glycopyrrolate/formoterol [18] have been approved in China.

The major metabolic pathways for aclidinium in humans are non-enzymatic and enzymatic hydrolysis of its carboxylic ester moiety, which produces two inactive metabolites, LAS34823 and LAS34850. Although the genetic locus of the enzyme responsible for the hydrolysis of aclidinium (butyrylcholinesterase) contains polymorphisms $[19,20]$, variation in pharmacokinetic (PK) variables for other LAMAs was low between different ethnicities in two studies [21, 22]; therefore, ethnicity was not expected to influence the PK of aclidinium/formoterol. This study aimed to bridge the known PK, safety, and tolerability characteristics of aclidinium bromide/formoterol fumarate $400 / 12 \mu \mathrm{g}$ twice daily in patients from China with moderate-to-severe COPD.

\section{Methods}

\subsection{Study Design}

This was an open-label, repeat-dose, 5-day bridging study (NCT03276078) carried out at a single site in China (Phase I Clinical Research Center, the First Hospital of Jilin University) between November 2017 and June 2018. As this was a bridging study, no control group was included. Patients were trained on inhaler use during screening, which took place up to 21 days before the first dose of study drug was administered (Fig. 1), and again on day 1. From day 1 to day 4, patients self-administered aclidinium/formoterol $400 / 12 \mu \mathrm{g}$ using a Genuair ${ }^{\circledR}$ dry powder inhaler (DPI) in the morning and evening. On day 5, patients took a morning dose only. All patients remained in the study center from day-1 until after sample collection and safety assessments on day 5 , and were discharged $48 \mathrm{~h}$ after the last dose on day 7. A follow-up visit for safety purposes was conducted within 5 days of the last sample being taken.

\subsection{Patients}

Patients (aged $\geq 40$ years) who were current or former smokers ( $\geq 10$ pack-years of smoking history), with a stable diagnosis ( $\geq 6$ months prior to screening) of moderate-to-severe COPD according to the Global Initiative for Chronic Obstructive Lung Disease (GOLD) guidelines [1] (post-bronchodilator forced expiratory volume in $1 \mathrm{~s}$ $\left[\mathrm{FEV}_{1}\right] \geq 30 \%$ and $<80 \%$ of the predicted value, $\mathrm{FEV}_{1} /$ forced vital capacity $<70 \%$ ), were eligible. Permitted medications included inhaled corticosteroids; continuous oral or parenteral corticosteroids (dose equivalent: $\leq 10 \mathrm{mg} /$ day prednisone; $10 \mathrm{mg}$ every other day); oxygen therapy $(<15 \mathrm{~h} /$ day $)$, provided treatment was stable $\geq 4$ weeks prior to screening; and selective $\beta$-blocking agents, provided
Fig. 1 Study design. BID twice daily, $D$ day

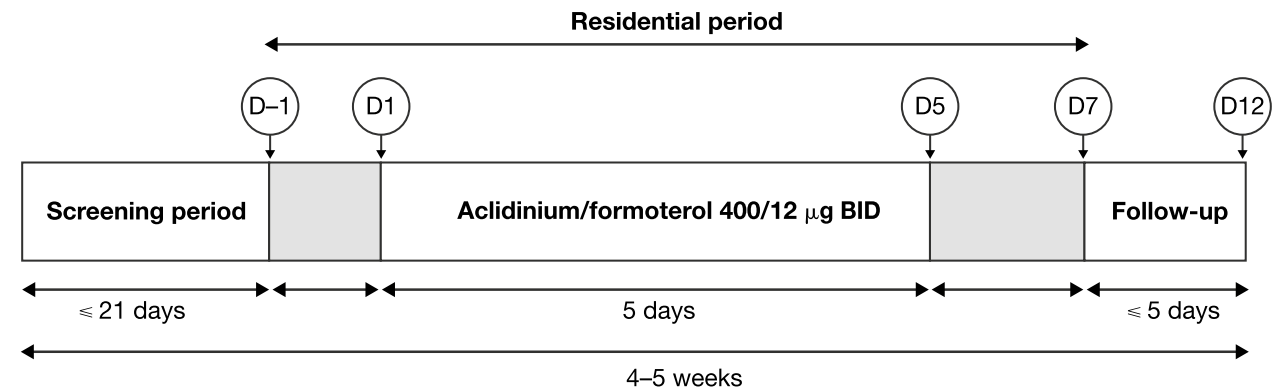


treatment was stable for $\geq 2$ weeks. Leukotriene modifiers and phosphodiesterase type 4 inhibitors were not permitted within 14 days prior to day-1. Patients with a history (or current diagnosis) of asthma, symptomatic bladder neck obstruction, acute urinary retention, symptomatic non-stable prostatic hypertrophy, or a body mass index (BMI) $\geq 40 \mathrm{~kg} / \mathrm{m}^{2}$ were excluded. For further details of permitted and prohibited medications, see Electronic Supplementary Table S1 and Table S2.

\subsection{Ethics Approval}

The Institutional Review Board of The First Hospital of Jilin University reviewed and approved the final protocol, any amendments, and the informed consent documentation. The study was performed in accordance with the Declaration of Helsinki and International Conference on Harmonisation Good Clinical Practice Guidelines, and conformed with local regulatory requirements.

\subsection{Pharmacokinetic Evaluations}

Blood samples were collected on day 1 at $0 \mathrm{~h}$ (approximately 15 min before the morning dose), then after 5,15 , and $30 \mathrm{~min}$, and $1,1.5,2,3,4,6,8$, and $12 \mathrm{~h}$ post-morning dose (12-h sample collected 5 min before the evening dose). On days $2-4$, blood samples were collected at 0 and $12 \mathrm{~h}$ (approximately $5 \mathrm{~min}$ before the morning and evening doses). On day 5, blood samples were collected at $0 \mathrm{~h}$ (approximately $5 \mathrm{~min}$ before the morning dose), then after 5 , 15 , and $30 \mathrm{~min}$, and 1, 1.5, 2, 3, 4, 6, 8, 12, 24, 36, and $48 \mathrm{~h}$ post-morning dose.

Plasma concentrations of aclidinium, formoterol, and the two aclidinium metabolites (LAS34823 and LAS34850) were extracted using solid-phase extraction (following precipitation of formoterol) and analyzed by liquid chromatography with tandem mass spectrometry (Covance Pharmaceutical R\&D Co., Ltd). The method was validated prior to sample analysis, and incurred sample reproducibility analyses were performed during the study; aclidinium, formoterol, LAS34823, and LAS34850 were within the accepted criteria for incurred sample reproducibility.

On day $1(0 \mathrm{~h})$, concentrations less than the lower limit of quantification were set to zero; after this point, concentrations below the limit of quantification were set to missing for all concentration profiles. Assessments included area under the concentration-time curve during a dosage interval $\left(\mathrm{AUC}_{\tau}\right)$; apparent total clearance of the drug from plasma after oral inhalation $(\mathrm{CL} / F)$; maximum concentration $\left(C_{\max }\right)$; metabolite ratio (MR); accumulation ratio $\left(R_{\mathrm{ac}}\right)$; elimination halflife $\left(t_{1 / 2}\right)$; time to reach $C_{\max }\left(T_{\max }\right)$; and apparent volume of distribution $(\mathrm{Vz} / F)$. PK parameters were analyzed by means of a non-compartmental analysis model developed using an internally validated software system, Phoenix WinNonLin ${ }^{\circledR}$ v6.4 (Certara L.P., Princeton, NJ, USA).

\subsection{Safety Evaluations}

Treatment-emergent adverse events (TEAEs; defined as any adverse event $[\mathrm{AE}]$ that started after the first dose of treatment or within 15 days of the final dose) were monitored and coded using the Medical Dictionary for Regulatory Activities (MedDRA) version 20.1. Clinical laboratory parameters, blood pressure, and 12-lead electrocardiogram data were also collected.

\subsection{Statistical Analysis}

A total of 20 patients were deemed sufficient to permit PK characterization. The PK analysis set comprised all patients who received one or more dose of study drug and had data for one or more of the following parameters: $C_{\max }$, steadystate $C_{\max }\left(C_{\text {max,ss }}\right), \mathrm{AUC}_{\tau}$, area under the plasma concentration-time curve from time zero to time of the last measurable concentration $\left(\mathrm{AUC}_{\text {last }}\right)$, or steady-state $\mathrm{AUC}_{\tau}\left(\mathrm{AUC}_{\tau, \mathrm{ss}}\right)$, and were assumed not to be affected by factors such as protocol deviations; the safety analysis set comprised all patients who received one or more doses of study drug. Given the exploratory nature of this study, descriptive statistics were used throughout and no formal statistical hypothesis testing or corrections for multiplicity were performed. All statistical tests were conducted using the SAS 9.3 Statistical Package (SAS Institute Inc., Cary, NC, USA).

\subsection{Results}

In total, 20 patients were included in the study. The mean age was 59.2 years, $15(75 \%)$ patients were male, and the mean BMI was $24.7 \mathrm{~kg} / \mathrm{m}^{2}$ (Table 1). Nine patients (45\%) had moderate COPD and 11 (55\%) had severe COPD. Mean pre-bronchodilator $\mathrm{FEV}_{1}$ was $1.4 \mathrm{~L}$, with a post-bronchodilator $\mathrm{FEV}_{1}$ of $54.1 \%$ of the predicted value; mean bronchial reversibility was $8.1 \%$.

\subsection{Pharmacokinetic Outcomes}

\subsubsection{Aclidinium}

The median (range) $T_{\max }$ was $0.08(0.08-0.50) \mathrm{h}$ on both day 1 and day $5 ; C_{\max }$ was $45.82 \mathrm{pg} / \mathrm{mL}$ on day 1 and $60.86 \mathrm{pg} / \mathrm{mL}$ on day 5 at $C_{\mathrm{max}, \mathrm{ss}}$; and $\mathrm{AUC}_{\tau}$ was $85.45 \mathrm{~h} \cdot \mathrm{pg} /$ $\mathrm{mL}$ on day 1 and $168.80 \mathrm{~h} \cdot \mathrm{pg} / \mathrm{mL}$ on day 5 (Table 2, Fig. 2). The between-patient variability in systemic exposure was high at both day $1\left(C_{\max }\right.$ coefficient of variation $[\mathrm{CV}] 84.5 \%$; $\left.\mathrm{AUC}_{\tau} \mathrm{CV} 79.0 \%\right)$ and day 5 ( $C_{\text {max,ss }} \mathrm{CV} 150.0 \% ; \mathrm{AUC}_{\tau, \mathrm{ss}}$ CV $82.2 \%$ ). On day 5, after reaching $C_{\text {max,ss }}$, aclidinium 
Table 1 Demographic and baseline characteristics

\begin{tabular}{|c|c|}
\hline & Safety analysis set $[n=20]$ \\
\hline Age, years [mean $(\mathrm{SD})]$ & $59.2(6.8)$ \\
\hline Male $[n(\%)]$ & $15(75)$ \\
\hline BMI, $\mathrm{kg} / \mathrm{m}^{2}$ [mean (SD)] & $24.7(3.3)$ \\
\hline \multicolumn{2}{|l|}{ Pre-bronchodilator } \\
\hline $\mathrm{FEV}_{1}, \mathrm{~L}[$ mean $(\mathrm{SD})]$ & $1.4(0.6)$ \\
\hline $\mathrm{FEV}_{1} \%$ predicted [mean (SD)] & $50.3(13.8)$ \\
\hline \multicolumn{2}{|l|}{ Post-bronchodilator } \\
\hline $\mathrm{FEV}_{1}, \mathrm{~L}[$ mean $(\mathrm{SD})]$ & $1.5(0.6)$ \\
\hline $\mathrm{FEV}_{1} \%$ predicted [mean (SD)] & $54.1(13.9)$ \\
\hline \multicolumn{2}{|l|}{ COPD severity } \\
\hline Moderate $^{\mathrm{a}}[n(\%)]$ & $9(45)$ \\
\hline Severe $^{\mathrm{b}}[n(\%)]$ & $11(55)$ \\
\hline \multicolumn{2}{|l|}{ Reversibility } \\
\hline Absolute, mL [mean (SD)] & $93.5(73.3)$ \\
\hline$\%$ [mean (SD)] & $8.1(8.1)$ \\
\hline
\end{tabular}

$B M I$ body mass index, $C O P D$ chronic obstructive pulmonary disease, $F E V_{1}$ forced expiratory volume in $1 \mathrm{~s}, S D$ standard deviation

${ }^{\mathrm{a}} 50 \% \leq \mathrm{FEV}_{1}<80 \%$ of the predicted value

${ }^{\mathrm{b}} 30 \% \leq \mathrm{FEV}_{1}<50 \%$ of the predicted value

concentrations declined in a generally biphasic manner, with a mean $t_{1 / 2}$ of $19.42 \mathrm{~h}$. The mean $\mathrm{CL} / F, \mathrm{Vz} / F$, and $R_{\mathrm{ac}}\left(C_{\max }\right)$ at day 5 were $3140 \mathrm{~L} / \mathrm{h}, 81,990 \mathrm{~L}$, and 1.30 , respectively.

\subsubsection{Formoterol}

The median (range) $T_{\max }$ was $1.00(0.08-3.00) \mathrm{h}$ on day 1 and $0.08(0.08-1.50) \mathrm{h}$ on day $5 ; C_{\max }$ was $4.79 \mathrm{pg} / \mathrm{mL}$ on day
1 and $6.47 \mathrm{pg} / \mathrm{mL}$ on day 5; and $\mathrm{AUC}_{\tau}$ was $22.78 \mathrm{~h} \cdot \mathrm{pg} / \mathrm{mL}$ on day 1 and $31.98 \mathrm{~h} \cdot \mathrm{pg} / \mathrm{mL}$ on day 5 (Table 2, Fig. 2). The between-patient variability in systemic exposure to formoterol was high at both day $1\left(C_{\max } \mathrm{CV} 62.8 \% ; \mathrm{AUC}_{\tau} \mathrm{CV}\right.$ $43.6 \%)$ and day $5\left(C_{\max } \mathrm{CV} 84.3 \%, \mathrm{AUC}_{\tau} \mathrm{CV} 51.6 \%\right)$. On day 5 , after reaching $C_{\text {max ss }}$, formoterol concentrations declined in a generally biphasic manner, with a mean $t_{1 / 2}$ of $14.06 \mathrm{~h}$. The plasma profile on day 5 was characterized by the presence of two peaks, one at $5 \mathrm{~min}$ post-dose and one at $1.5 \mathrm{~h}$ post-dose; the highest peak at $5 \mathrm{~min}$ was not present on day 1 . The mean $\mathrm{CL} / F, \mathrm{Vz} / F$, and $R_{\mathrm{ac}}\left(C_{\max }\right)$ were $422.2 \mathrm{~L} / \mathrm{h}$, $8284 \mathrm{~L}$, and 1.38 , respectively.

\subsubsection{LAS34850}

The median $T_{\max }$ (range) of LAS34850 was $3.00(1.50-6.00) \mathrm{h}$ on day 1 and $3.00(0.08-4.00) \mathrm{h}$ on day $5 ; C_{\max }$ was $3149 \mathrm{pg} / \mathrm{mL}$ on day 1 and $3691 \mathrm{pg} / \mathrm{mL}$ on day 5; and $\mathrm{AUC}_{\tau}$ was 20,330 $\mathrm{h} \cdot \mathrm{pg} / \mathrm{mL}$ on day 1 and $27,300 \mathrm{~h} \cdot \mathrm{pg} / \mathrm{mL}$ on day 5 (Electronic Supplementary Table S3). The between-patient variability in systemic exposure to LAS34850 was high at both day 1 $\left(C_{\max } \mathrm{CV} 55.6 \% ; \mathrm{AUC}_{\tau} \mathrm{CV} 54.2 \%\right)$ and day $5\left(C_{\max } \mathrm{CV}\right.$ $56.0 \%$; $\left.\mathrm{AUC}_{\tau} \mathrm{CV} 52.3 \%\right)$. Following $C_{\max }$, concentrations declined in a biphasic manner on day 5 , with a mean $t_{1 / 2}$ of $20.95 \mathrm{~h}$. The mean metabolite-to-parent ratios for LAS34850 were high: 60.65-68.72 for $C_{\max }$ and $161.70-237.90$ for $\mathrm{AUC}_{\tau}$ (Electronic Supplementary Table S3).

\subsubsection{LAS34823}

The median $T_{\text {max }}$ (range) of LAS34823 was $1.75(0.08-4.00) \mathrm{h}$ and $0.50(0.08-3.00) \mathrm{h}$ on day 1 and day 5 , respectively; $C_{\max }$ was $38.82 \mathrm{pg} / \mathrm{mL}$ on day 1 and $81.02 \mathrm{pg} / \mathrm{mL}$ on day 5 ; and

Table 2 Pharmacokinetic parameters of aclidinium and formoterol (pharmacokinetic analysis set)

\begin{tabular}{|c|c|c|c|c|}
\hline \multirow[t]{2}{*}{ Parameter } & \multicolumn{2}{|l|}{ Aclidinium } & \multicolumn{2}{|l|}{ Formoterol } \\
\hline & Day $1[n=20]$ & Day $5[n=19]$ & Day $1[n=20]$ & Day $5[n=19]$ \\
\hline$C_{\max }, \mathrm{pg} / \mathrm{mL}[\operatorname{mean}(\mathrm{CV} \%)]$ & $45.82(84.5)$ & $60.86(150.0)$ & $4.79(62.8)$ & $6.47(84.3)$ \\
\hline$T_{\max }, \mathrm{h}$ [median (range)] & $0.08(0.08-0.50)$ & $0.08(0.08-0.50)$ & $1.00(0.08-3.00)$ & $0.08(0.08-1.50)$ \\
\hline $\mathrm{AUC}_{\tau}, \mathrm{h} \cdot \mathrm{pg} / \mathrm{mL}[$ mean $(\mathrm{CV} \%)]$ & $85.45(79.0)$ & $168.80(82.2)$ & $22.78(43.6)$ & $31.98(51.6)$ \\
\hline $\mathrm{AUC}_{\text {last }}, \mathrm{h} \cdot \mathrm{pg} / \mathrm{mL}[$ mean $(\mathrm{CV} \%)]$ & $78.61(90.7)$ & & $20.04(64.2)$ & \\
\hline$t_{1 / 2}, \mathrm{~h}[$ mean (range)] & & $19.42(4.30-45.2)$ & & $14.06(4.97-24.4)$ \\
\hline $\mathrm{CL} / F, \mathrm{~L} / \mathrm{h}[$ mean (range) $]$ & & $3140(1120-12,400)$ & & $422.2(199-868)$ \\
\hline$V z / F, L[$ mean (range)] & & $81,990(9140-375,000)$ & & $8284(2780-24,100)$ \\
\hline$R_{\mathrm{ac}}\left(C_{\mathrm{max}}\right)[$ mean $(\mathrm{CV} \%)]$ & & $1.30(216.6)$ & & $1.38(90.2)$ \\
\hline$R_{\mathrm{ac}}\left(\mathrm{AUC}_{\tau}\right)[$ mean $(\mathrm{CV} \%)]$ & & $1.97(108.9)$ & & $1.44(56.3)$ \\
\hline
\end{tabular}

Day 5 data were recorded at steady state. Data are expressed as geometric mean unless otherwise indicated

$A U C_{\text {last }}$ area under the plasma concentration-time curve from time zero to the time of the last quantifiable concentration, $A U C_{\tau}$ area under the concentration-time curve during a dosage interval $\left(_{\tau}\right), C L / F$ apparent total clearance of the drug from plasma after oral inhalation, $C_{m a x}$ maximum concentration, $C V \%$ coefficient of variation, $R_{a c}\left(A U C_{\tau}\right)$ accumulation ratio calculated from $\mathrm{AUC}_{\tau}, R_{a c}\left(C_{\max }\right)$ accumulation ratio calculated from $\mathrm{C}_{\max }, t_{1 / 2}$ elimination half-life, $T_{\max }$ time to reach $C_{\max }, V z / F$ apparent volume of distribution 


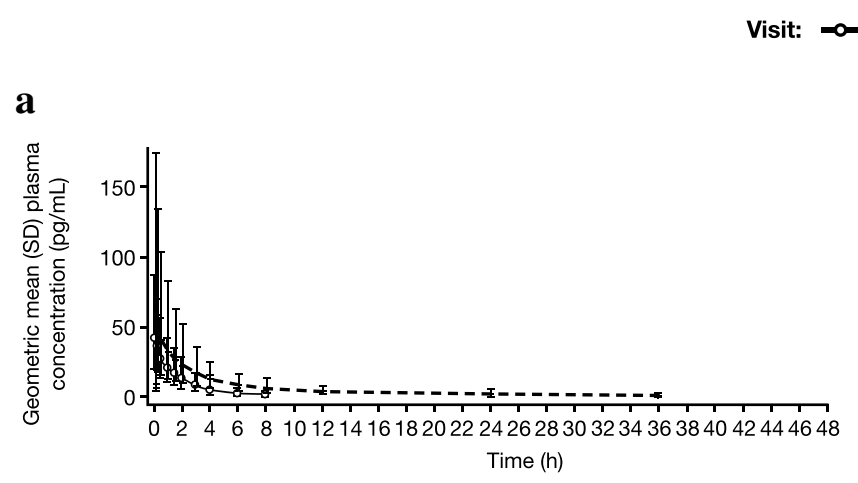

\section{b}
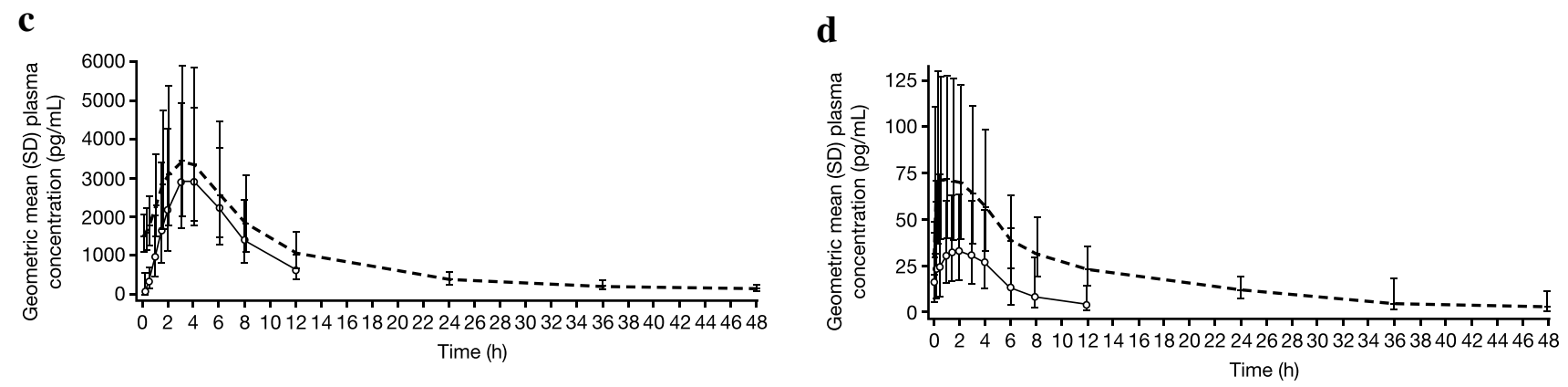

Fig. 2 Geometric mean plasma concentrations of a aclidinium, b formoterol, c LAS34850, and d LAS34823 (pharmacokinetic analysis set). SD standard deviation

$\mathrm{AUC}_{\tau}$ was $252.9 \mathrm{~h} \cdot \mathrm{pg} / \mathrm{mL}$ on day 1 and $540.9 \mathrm{~h} \cdot \mathrm{pg} / \mathrm{mL}$ on day 5 (Electronic Supplementary Table S3). The betweenpatient variability in systemic exposure to LAS34823 was high at both day $1\left(C_{\max } \mathrm{CV} 86.6 \%\right.$; $\left.\mathrm{AUC}_{\tau} \mathrm{CV} 60.6 \%\right)$ and day 5 ( $C_{\max } \mathrm{CV}$ 69.5\%; $\mathrm{AUC}_{\tau} \mathrm{CV} 55.0 \%$ ). Following $C_{\max }$, concentrations declined in a multiphasic manner on day 5 , with a mean $t_{1 / 2}$ of $17.34 \mathrm{~h}$. The mean metabolite-to-parent ratios for LAS34823 were high: $0.85-1.33$ for $C_{\max }$ and 2.75-3.20 for $\mathrm{AUC}_{\tau}$ (Electronic Supplementary Table S3).

Of note, several patients showed an anomalously low exposure to all four analytes (i.e., nearly flat concentration-time profiles) on day 1 and/or day 5 (Electronic Supplementary Fig. S1), indicative of a failure to deliver the complete dose, likely due to poor inhalation technique.

\subsection{Safety Evaluations}

Overall, aclidinium/formoterol 400/12 $\mu \mathrm{g}$ twice daily was well-tolerated. In total, nine TEAEs were reported in five patients (Electronic Supplementary Table S4), including one serious AE that resulted in discontinuation (bronchitis, possibly not related to treatment). All TEAEs were mild in severity, except for bronchitis (severe) and blood pressure increased (moderate). Four AEs were considered to be related to treatment by the investigator. The most common TEAE was proteinuria $(n=3)$, although two of these events were present at screening. Blood pressure and heart rate were stable throughout the duration of the study (Electronic Supplementary Fig. S2).

\section{Discussion}

This study characterized the PK, safety, and tolerability of aclidinium/formoterol 400/12 $\mu \mathrm{g}$ twice daily in patients from China with moderate-to-severe COPD. When compared with previous studies, the demographic and baseline characteristics of the study population were found to be representative of the intended COPD patient population [23]. Moreover, aclidinium/formoterol was well-tolerated, and safety outcomes were similar to the known safety profile of aclidinium and formoterol in other populations [24-26].

While it is important to note that differences in PK between healthy volunteers and patients with COPD may be due to the disease itself, a number of previous studies have examined the single- and multiple-dose PK of aclidinium/formoterol in both healthy volunteers [27] and those with COPD [28]. In a phase IIa, multiple-dose study of 24 patients in the US with moderate-to-severe COPD who received aclidinium/formoterol $400 / 12 \mu \mathrm{g}$, day $1 C_{\max }$ and area under the plasma concentration-time curve $\left(\mathrm{AUC}_{0-t}\right)$ for aclidinium were more than double the levels found in this analysis (102.0 pg/mL and $228.30 \mathrm{~h} \cdot \mathrm{pg} / \mathrm{mL}$, respectively), with a similar $T_{\max }$ of $5 \mathrm{~min}$ post-dose [28]. This difference was maintained at 5 days, where $C_{\max , \mathrm{ss}}$ was $128.4 \mathrm{pg} / \mathrm{mL}$ 
and $\mathrm{AUC}_{0-t}$ steady state was $404.3 \mathrm{~h} \cdot \mathrm{pg} / \mathrm{mL}$. A similar pattern was found with formoterol, where day $1 C_{\max }$ and $\mathrm{AUC}_{0-t}$ were approximately doubled $(9.6 \mathrm{pg} / \mathrm{mL}$ and 42.3 $\mathrm{h} \cdot \mathrm{pg} / \mathrm{mL}$, respectively), and day $5 C_{\max }$ was more than doubled $(16.7 \mathrm{pg} / \mathrm{mL})$, compared with this study. Despite these differences, the aclidinium $R_{\mathrm{ac}}(1.38)$ was similar to this study (formoterol value was not disclosed). In a phase I, single-dose study of 30 healthy volunteers in Germany who received aclidinium/formoterol $400 / 12 \mu \mathrm{g}$, aclidinium $C_{\max }$ was six times greater $(270 \mathrm{pg} / \mathrm{mL})$ and $\mathrm{AUC}_{0-t}$ was three times higher $(229 \mathrm{~h} \cdot \mathrm{pg} / \mathrm{mL})$ than the values observed in this study, although $T_{\max }$ was comparable $(0.08 \mathrm{~h})$ [27]. In addition, formoterol PK values were approximately double the values in this study $\left(C_{\max } 9.3 \mathrm{pg} / \mathrm{mL} ; \mathrm{AUC}_{0-t} 32.4 \mathrm{~h} \cdot \mathrm{pg} / \mathrm{mL}\right)$, with a comparable $T_{\max }$ of $0.08 \mathrm{~h}$.

A number of PK studies examining aclidinium $400 \mu \mathrm{g}$ monotherapy, which has comparable PK as the combination product, have also been conducted [29, 30]. In a phase I, multiple-dose study of 30 healthy US volunteers receiving aclidinium $400 \mu \mathrm{g}, C_{\max }$ and $\mathrm{AUC}_{0-t}$ were both approximately four times greater than in this study at day 1 (194.2 $\mathrm{pg} / \mathrm{mL}$ and $324.9 \mathrm{~h} \cdot \mathrm{pg} / \mathrm{mL}$, respectively), with an increase of four times and three times, respectively, on the evening of day 7 compared with day 5 in this study $\left(C_{\max }\right.$ $240.5 \mathrm{pg} / \mathrm{mL}$ and $\mathrm{AUC}_{0-t} 468.4 \mathrm{~h} \cdot \mathrm{pg} / \mathrm{mL}$ ) [29]; however, $T_{\max }$ remained similar $(0.08 \mathrm{~h})$. A phase I, open-label, multiple-dose PK study of 24 patients from Germany with COPD segregated patients by age group (younger patients, mean age 53 years; older patients, mean age 73 years; both $n=12$ ) [30]. Patients receiving aclidinium $400 \mu \mathrm{g}$ had a $C_{\max }$ of 82.3 and $71.2 \mathrm{pg} / \mathrm{mL}$, with an $\mathrm{AUC}_{\tau}$ of $193.5 \mathrm{~h} \cdot \mathrm{pg} / \mathrm{mL}$ and $171.3 \mathrm{~h} \cdot \mathrm{pg} / \mathrm{mL}$ on day 1 for younger and older patients, respectively, approximately double the values found in this study. These levels were maintained at day $3\left(C_{\max } 86.1\right.$ and $67.8 \mathrm{pg} / \mathrm{mL}$, and $\mathrm{AUC}_{\tau} 199.6$ and $\left.191.1 \mathrm{~h} \cdot \mathrm{pg} / \mathrm{mL}\right) . T_{\max }$ occurred slightly later than in this study, at 0.17 and $0.25 \mathrm{~h}$ for younger and older patients, respectively, at day 1 , and $0.25 \mathrm{~h}$ for both patient age groups at day 3 .

In comparing these data, it would appear that $C_{\max }$ and $\mathrm{AUC}_{\tau}$ values were lower in Chinese patients when compared with the largely Caucasian patient populations of the US and German studies. However, $T_{\max }$ values were generally similar, except for German patients in the de la Motte study, who had a longer $T_{\max }$ in both younger and older patient groups $[28,30]$. The lower exposures noted in Chinese patients are likely related to the suboptimal inhalation technique in this study, as discussed in the limitations.

Limitations of this study include the low patient numbers; however, the number of patients included is typical of a bridging study. The PK of inhaled products, either from a DPI or a metered-dose inhaler, is largely dependent on a proper inhalation technique. Drugs such as aclidinium have very poor oral availability, while formoterol has modest oral availability; therefore, the majority of systemic exposure comes from drugs deposited in the lung [14, 15, 31, 32]. Thus, the high between-patient variability observed in some patients is likely due to a suboptimal inhalation technique, particularly for formoterol on day 1 ; numerous patients did not have the expected early peak in $T_{\max }$ indicative of lung absorption, but rather had a median $T_{\max }$ at approximately $1 \mathrm{~h}$ post-treatment, suggesting primarily gastrointestinal absorption $[14,15]$. Furthermore, although the day 5 formoterol profiles showed consistently earlier $T_{\max }$ at $5 \mathrm{~min}$ (indicative of lung absorption), reflecting a better inhalation technique, many patients also had secondary peaks in $T_{\max }$ at approximately $2 \mathrm{~h}$, indicative of gastrointestinal absorption $[14,15]$. In addition, several patients had almost flat profiles for both aclidinium and formoterol, indicating a lack of complete dose delivery. Several other potential causes of between-patient variability have been reported and should also be given consideration.

\section{Conclusions}

In summary, aclidinium/formoterol 400/12 $\mu$ g was welltolerated in patients from China with moderate-to-severe COPD, and safety findings were consistent with the known safety profile of aclidinium and formoterol. However, a suboptimal inhalation technique among some patients likely influenced absorption of aclidinium/formoterol, leading to lower exposure and contributing to the high between-patient variability in PK characteristics.

Supplementary Information The online version contains supplementary material available at https://doi.org/10.1007/s40268-021-00374-z.

Acknowledgements Medical writing support, under the direction of the authors, was provided by Richard Knight, PhD, CMC Connect, McCann Health Medical Communications, and funded by AstraZeneca, in accordance with Good Publication Practice (GPP3) guidelines [33].

\section{Declarations}

Funding This work was supported by the National Major Scientific and Technological Special Project for Significant New Drug Development during the Thirteenth Five-Year Plan Period of China (Project: 2017ZX09304004, 2017ZX09101001-002-004), the National Natural Science Foundation of China (Project: 81602897), and the National Major Scientific and Technological Special Project for "Significant New Drugs Development" during the Thirteenth Five-Year Plan Period of China (No. 2018ZX09301007005). Further funding was received from AstraZeneca.

Conflicts of interest Sami Z. Daoud, Michael S. Gillen, Maria Heijer and Eduard Molins are employed by AstraZeneca, and Esther GarciaGil and Natalia Calderon are former employees of AstraZeneca. The remaining authors declare that the research was conducted in the absence of any commercial or financial relationships that could be construed as a potential conflict of interest. 
Availability of data and material This manuscript has associated data in a repository. Data underlying the findings described in this manuscript, including individual de-identified participant data, protocols and clinical trial documents, may be obtained in accordance with AstraZeneca's data-sharing policy (described at https://astrazenecagrouptrials.pharm acm.com/ST/Submission/Disclosure) through Vivli (https://vivli.org/).

Code availability Not applicable.

Author contributions Sami Z. Daoud, Michael S. Gillen, Natalia Calderon, Eduard Molins, and Esther Garcia-Gil contributed to the conception and design of the study; Hong Zhang, Hong Chen, Qianqian Li, and Yanhua Ding contributed to the design of the study; Hong Zhang, Hong Chen, Qianqian Li, Chengjiao Liu, and Yanhua Ding performed the study; and Hong Zhang and Yanhua Ding developed the first draft. All authors contributed to the interpretation and revision of the manuscript for intellectual content and provided final approval.

Ethics approval The Institutional Review Board of The First Hospital of Jilin University reviewed and approved the final protocol, any amendments, and the informed consent documentation. The study was performed in accordance with the Declaration of Helsinki and International Conference on Harmonisation Good Clinical Practice Guidelines, and conformed with local regulatory requirements.

Consent to participate All patients provided written, informed consent prior to the conduct of any study-specific procedures.

Consent for publication Not applicable.

Open Access This article is licensed under a Creative Commons Attribution-NonCommercial 4.0 International License, which permits any non-commercial use, sharing, adaptation, distribution and reproduction in any medium or format, as long as you give appropriate credit to the original author(s) and the source, provide a link to the Creative Commons licence, and indicate if changes were made. The images or other third party material in this article are included in the article's Creative Commons licence, unless indicated otherwise in a credit line to the material. If material is not included in the article's Creative Commons licence and your intended use is not permitted by statutory regulation or exceeds the permitted use, you will need to obtain permission directly from the copyright holder. To view a copy of this licence, visit http://creativecommons.org/licenses/by-nc/4.0/.

\section{References}

1. Global Initiative for Chronic Obstructive Lung Disease. Global strategy for the diagnosis, management, and prevention of chronic obstructive pulmonary disease. 2021. https://goldcopd.org/2021gold-reports/. Accessed 12 May 2021.

2. GBD. 2017 Causes of Death Collaborators. Global, regional, and national age-sex-specific mortality for 282 causes of death in 195 countries and territories, 1980-2017: a systematic analysis for the Global Burden of Disease Study 2017. Lancet. 2018;392:1736-88.

3. Zhong N, Wang C, Yao W, Chen P, Kang J, Huang S, et al. Prevalence of chronic obstructive pulmonary disease in China: a large, population-based survey. Am J Respir Crit Care Med. 2007;176:753-60.

4. Cazzola M, Rogliani P, Matera MG. Aclidinium bromide/formoterol fumarate fixed-dose combination for the treatment of chronic obstructive pulmonary disease. Expert Opin Pharmacother. $2013 ; 14: 775-81$.
5. Braido F, Baiardini I, Cazzola M, Brusselle G, Marugo F, Canonica GW. Long-acting bronchodilators improve health related quality of life in patients with COPD. Respir Med. 2013;107:1465-80.

6. Beeh KM, Burgel PR, Franssen FME, Lopez-Campos JL, Loukides S, Hurst JR, et al. How do dual long-acting bronchodilators prevent exacerbations of chronic obstructive pulmonary disease? Am J Respir Crit Care Med. 2017;196:139-49.

7. Novartis Pharmaceuticals UK Ltd. Ultibro ${ }^{\circledR}$ Breezhaler ${ }^{\circledR}$ summary of product characteristics. 2020. http://www.medicines.org.uk/ emc/medicine/29533. Accessed 29 May 2020.

8. Novartis Pharmaceuticals Corporation. Utibron ${ }^{\mathrm{TM}}$ Neohaler $^{\circledR}$ highlights of prescribing information. 2017. https://www.acces sdata.fda.gov/drugsatfda_docs/label/2017/207930s002lbl.pdf. Accessed 13 Oct 2020.

9. GlaxoSmithKline PLC. Anoro ${ }^{\circledR}$ Ellipta ${ }^{\circledR}$ summary of product characteristics. 2019. https://www.medicines.org.uk/emc/medic ine/28949/. Accessed 29 May 2020.

10. Boehringer Ingelheim GmbH. Stiolto ${ }^{\mathrm{TM}}$ Respimat $^{\circledR}$ highlights of prescribing information. 2018. https://www.accessdata.fda.gov/ drugsatfda_docs/label/2018/206756s009lbl.pdf. Accessed 29 May 2020.

11. Boehringer Ingelheim GmbH. Spiolto ${ }^{\circledR}$ Respimat $^{\circledR}$ summary of product characteristics. 2019. https://www.medicines.org.uk/emc/ medicine/30495. Accessed 29 May 2020.

12. AstraZeneca PLC. Bevespi ${ }^{\circledR}$ Aerosphere ${ }^{\circledR}$ highlights of prescribing information. 2020. https://www.azpicentral.com/bevespi/beves pi.pdf. Accessed 11 Aug 2020.

13. AstraZeneca PLC. Bevespi ${ }^{\circledR}$ Aerosphere ${ }^{\circledR}$ summary of product characteristics. 2018. https://www.ema.europa.eu/en/medicines/ human/EPAR/bevespi-aerosphere. Accessed 3 Sep 2020.

14. AstraZeneca PLC. Duaklir ${ }^{\circledR}$ Genuair $^{\circledR}$ highlights of prescribing information. 2019. https://www.accessdata.fda.gov/drugsatfda docs/label/2019/210595lbl.pdf. Accessed 29 May 2020.

15. AstraZeneca PLC. Duaklir ${ }^{\circledR}$ Genuair $^{\mathrm{TM}}$ summary of product characteristics. 2019. http://www.medicines.org.uk/emc/medic ine/29652. Accessed 29 May 2020.

16. Sosei Heptares. Sosei Heptares annoucnes that Ultibro ${ }^{\circledR}$ Breezhaler ${ }^{\circledR}$ and Seebri ${ }^{\circledR}$ Breezhaler ${ }^{\circledR}$ launched in China for the treatment of COPD. 2019. https://soseiheptares.com/news/509/ 129/osei-Heptares-announces-that-Ultibro-Breezhaler-and-Seebri-Breezhaler-launched-in-China-for-the-treatment-of-COPD. html. Accessed 13 May 2021.

17. GlaxoSmithKline PLC. GSK Anoro Ellipta, a new once-daily dual bronchodilators treatment for COPD approved in China. 2018. https://www.gsk-china.com/en-gb/media/press-releases/2018/ gsk-anoro-ellipta-a-new-once-daily-dual-bronchodilators-treat ment-for-copd-approved-in-china/. Accessed 13 May 2021.

18. AstraZeneca PLC. Bevespi aerosphere approved in China for patients with COPD. 2020. https://www.astrazeneca.com/mediacentre/press-releases/2020/bevespi-aerosphere-approved-in-chinafor-patients-with-copd.html. Accessed 13 May 2021.

19. Albertí J, Martinet A, Sentellas S, Salvà M. Identification of the human enzymes responsible for the enzymatic hydrolysis of aclidinium bromide. Drug Metab Dispos. 2010;38:1202-10.

20. Sentellas S, Ramos I, Albertí J, Salvà M, Antón F, Miralpeix M, et al. Aclidinium bromide, a new, long-acting, inhaled muscarinic antagonist: in vitro plasma inactivation and pharmacological activity of its main metabolites. Eur J Pharm Sci. 2010;39:283-90.

21. Reisner C, Miller J, DePetrillo P, Maes A, Siddiqui S, Martin UJ. Pharmacokinetics and safety of a single dose of the novel LAMA/LABA fixed-dose combination of glycopyrronium/formoterol fumarate dihydrate metered dose inhaler, formulated using co-suspension delivery technology, in Japanese healthy subjects. Pulm Pharmacol Ther. 2018;53:33-8.

22. Ferguson GT, Rodriguez-Roisin R, Reisner C, Maes A, Siddiqui S, Martin UJ. Pharmacokinetics of glycopyrronium/formoterol 
fumarate dihydrate delivered via metered dose inhaler using cosuspension delivery technology in patients with moderate-to-very severe COPD. Int J Chron Obstruct Pulmon Dis. 2018;13:945-53.

23. Bateman ED, Chapman KR, Singh D, D’Urzo AD, Molins E, Leselbaum A, et al. Aclidinium bromide and formoterol fumarate as a fixed-dose combination in COPD: pooled analysis of symptoms and exacerbations from two six-month, multicentre, randomised studies (ACLIFORM and AUGMENT). Respir Res. 2015;16:92.

24. D'Urzo AD, Rennard SI, Kerwin EM, Mergel V, Leselbaum AR, Caracta CF. Efficacy and safety of fixed-dose combinations of aclidinium bromide/formoterol fumarate: the 24-week, randomized, placebo-controlled AUGMENT COPD study. Respir Res. 2014; $15: 123$.

25. Singh D, Jones PW, Bateman ED, Korn S, Serra C, Molins E, et al. Efficacy and safety of aclidinium bromide/formoterol fumarate fixed-dose combinations compared with individual components and placebo in patients with COPD (ACLIFORM-COPD): a multicentre, randomised study. BMC Pulm Med. 2014;14:178.

26. Sethi S, Kerwin E, Watz H, Ferguson GT, Mroz RM, Segarra R, et al. AMPLIFY: a randomized, Phase III study evaluating the efficacy and safety of aclidinium/formoterol vs monocomponents and tiotropium in patients with moderate-to-very severe symptomatic COPD. Int J Chron Obstruct Pulmon Dis. 2019;14:667-82.

27. Fuhr R, Leselbaum A, Aubets J. Pharmacokinetics of aclidinium bromide/formoterol fumarate fixed-dose combination compared with individual components: a phase 1, open-label, single-dose study. Clin Pharmacol Drug Dev. 2016;5:109-17.
28. Fogarty C, Ortiz S. Pharmacokinetics, safety, and tolerability of aclidinium/formoterol fixed dose combination via Pressair/Genuair vs formoterol via Foradil Aerolizer in patients with moderate to severe COPD. Chest. 2014;146(4 Suppl 2):45A.

29. Lasseter K, Dilzer S, Jansat JM, Garcia Gil E, Caracta CF, Ortiz S. Safety and pharmacokinetics of multiple doses of aclidinium bromide administered twice daily in healthy volunteers. Pulm Pharmacol Ther. 2012;25:193-9.

30. de la Motte S, Beier J, Schmid K, Pascual S, Jansat JM, Gil EG. Pharmacokinetics and safety of aclidinium bromide in younger and elderly patients with chronic obstructive pulmonary disease. Int J Clin Pharmacol Ther. 2012;50:403-12.

31. Novartis International AG. Foradil. Summary of product characteristics. 2013. http://www.medicines.org.uk/emc/medicine/1286/ SPC/foradil/. Accessed 2 Mar 2016.

32. Prat M, Fernández D, Buil MA, Crespo MI, Casals G, Ferrer M, et al. Discovery of novel quaternary ammonium derivatives of (3R)-quinuclidinol esters as potent and long-acting muscarinic antagonists with potential for minimal systemic exposure after inhaled administration: identification of (3R)-3-\{[hydroxy(di2-thienyl)acetyl]oxy \}-1-(3-phenoxypropyl)-1-azoniabicyclo[2.2 .2] octane bromide (aclidinium bromide). J Med Chem. 2009;52:5076-92.

33. Battisti WP, Wager E, Baltzer L, Bridges D, Cairns A, Carswell CI, et al. Good publication practice for communicating company-sponsored medical research: GPP3. Ann Intern Med. 2015;163:461-4. 